\title{
MicroRNAs: A Puzzling Tool in Cancer Diagnostics and Therapy
}

\author{
BARBARA D'ANGELO ${ }^{1}$, ELISABETTA BENEDETTI ${ }^{2}$, ANNAMARIA CIMINI $^{1,2,3}$ and ANTONIO GIORDANO ${ }^{1,4}$ \\ ${ }^{1}$ Sbarro Institute for Cancer Research and Molecular Medicine and Center for Biotechnology, \\ Temple University, Philadelphia, PA, U.S.A.; \\ ${ }^{2}$ Department of Life, Health and Environmental Sciences, University of L'Aquila, L'Aquila, Italy; \\ ${ }^{3}$ National Institute for Nuclear Physics (INFN), Gran Sasso National Laboratory (LNGS), Assergi, Italy; \\ ${ }^{4}$ Department of Medicine, Surgery and Neuroscience, University of Siena, Siena, Italy
}

\begin{abstract}
MicroRNAs (miRNAs) constitute a dominating class of small RNAs that regulate diverse cellular functions. Due the pivotal role of miRNAs in biological processes, a deregulated miRNA expression is likely involved in human cancers. MicroRNAs possess tumor suppressor capability, as well as display oncogenic characteristics. Interestingly, miRNAs exist in various biological fluids as circulating entities. Changes in the profile of circulating miRNAs are indicative of pathophysiological conditions in human cancer. This concept has led to consider circulating miRNAs valid biomarkers in cancer diagnostics. Furthermore, current research promotes the use of miRNAs as a target in cancer therapy. However, miRNAs are an evolving research field. Although miRNAs have been demonstrated to be potentially valuable tools both in cancer diagnosis and treatment, a greater effort should be made to improve our understanding of miRNAs biology. This review describes the biology of microRNAs, emphasizing on the use of miRNAs in cancer diagnostics and therapy.
\end{abstract}

Different classes of small non-coding RNA molecules, including microRNA (miRNA), small interfering RNA (siRNA) and PIWI-interacting RNA (piRNA) have been identified in eukaryotic organisms. Initially, non-coding RNAs

This article is freely accessible online.

Correspondence to: Antonio Giordano, Sbarro Institute for Cancer Research and Molecular Medicine and Center for Biotechnology, Temple University, Philadelphia, PA, U.S.A. Tel: +12152049520 , Fax: +1 2152049522, e-mail: giordano@temple.edu and Barbara D'Angelo, Sbarro Institute for Cancer Research and Molecular Medicine and Center for Biotechnology, Temple University, Philadelphia, PA, U.S.A. Tel: +1 2152049521, Fax: +1 2152049522, e-mail: barbara.dangelo@temple.edu

Key Words: MicroRNAs, circulating microRNAs, cancer, review. were believed to lack a particular function, hence they were classified as RNA junk (1). Although the definition of RNA junk is still elusive (1), several categories of small RNAs are now recognized for their capability to control gene expression and participate in cell signaling regulation. Distinctive features of small RNAs are their length (20-30 nucleotides), as well as their association with Argonaute-2 proteins (2). MicroRNAs constitute a dominating class of small RNAs that regulate diverse cellular functions, including apoptosis (3), metabolism (4), as well as cell growth and differentiation $(5,6)$. Due the pivotal role of miRNAs in biological processes, deregulation in miRNAs expression alters normal cell functions, hence participating in the development of human disease, including cancer. In this review we sought to describe the biology of microRNAs, outlining the potential use of miRNAs in cancer diagnostics and therapy.

\section{MicroRNA Biogenesis and Function}

MiRNAs are endogenous, non-coding RNA molecules, of 18-22 nucleotides length, capable of modulating negatively gene expression at the post-transcriptional level. miRNAs are made by a multistep process that initiates in the nucleus and ends in the cytoplasm.

The majority of miRNAs are generated from "independent" genes (also known as intergenic miRNA genes), so called as they retain their set of promoters and regulatory elements (7). However, about $25 \%$ of miRNA genes is a portion of introns (intronic miRNAs) placed within the sequence of canonical genes. Intronic miRNAs share mutual promoters with genes wherein they are integrated. After being produced as a single transcript, an intronic miRNA is processed from introns sequences (8). Another category of RNA molecules is represented by miRNAs generated by entire intron sequences. These miRNAs are known as mirtrons (8-10). 
The first step in the biogenesis of miRNA genes involves the activation of the RNA polymerase II enzyme that produces primary miRNA transcripts (pri-miRNAs). PrimiRNAs are hairpin precursors of about 70 nucleotides and are further processed into shorter (10 nucleotides smaller), transcripts (pre-miRNAs) by the Drosha endonuclease complex (7). An exception to this mechanism is represented by the mirtrons pathway in which the generation of miRNAs does not require the activity of the Drosha complex; instead these pre-miRNAs are originated directly from the mirtron transcript, by splicing mechanisms (9). However, several other characteristics distinguish the processing mirtrons from canonical miRNAs. For a comprehensive study on mirtrons biogenesis, refer to Wen et al. (10).

Once produced, pre-miRNAs are transported to the cytoplasm where they are cleaved by the endonuclease enzyme Dicer into double-stranded 20-21 nucleotides miRNAs, each containing a guide strand, which is complementary to the target RNA messenger (mRNA), and a pairing strand referred as passenger strand. When a duplex miRNA unwinds, the passenger strand is degraded, while the guide strand (now considered as mature miRNA) is associated with Argonaute- 2 proteins that initiate the loading of the mature miRNA into the miRNA-induced silencing complex (miRISC) (11). Once assembled, miRISC targets and silences specific mRNAs. The selection of mRNA by the miRISC is determined by the degree of complementarity between the region at 5' end of the miRNA-loaded in the complex and 3'UTR site on the mRNA. miRISC can perform two alternative silencing mechanisms: it can inhibit the translation of mRNA or, induce the mRNA degradation. The nature of control adopted by miRISC depends on whether the sequence of the miRNA-loaded in the complex shows partial or full complementarity with the sequence of the target mRNA: sequences that match only partially lead to repression of the translation, while a sequence perfect matching triggers mRNA degradation $(8,12)$.

\section{MicroRNAs and Cancer}

Due the pivotal role of miRNAs in biological processes, deregulation in miRNAs expression participates in cancer initiation and progression (13). Our collaborative study by Cattaneo et al. has determined a specific miRNA signature with a potential biomarker feature in acute myeloid leukemia (14). Similarly, numerous investigations have approached the identification of specific miRNAs as biomarkers and biotargets in human cancer (15).

MicroRNAs either have tumor suppressor capability (e.g., miR-29b and miRNA-30-5p) $(16,17)$ or display oncogenic characteristics (e.g., mir-17-92 cluster) (18), both of which influence cell growth (19).
Similarly to proteins, miRNA dysfunction depends on several reasons: alteration in miRNA expression can be a result of miRNA gene mutations (20), epigenetic modifications (21) or deficiency in the miRNA processing pathway (22). Also, genetic mutation, as well as epigenetic modification of miRNAs genes, have been correlated with cancer (8).

\section{Circulating miRNAs in Cancer Diagnosis}

Successive to their initial identification in tissues, microRNAs have been found in various biological fluids, including plasma, serum, saliva, milk and cerebrospinal fluid. Non-cellular microRNAs, also known as circulating miRNAs, display a high grade of stability despite their RNA nature (23). Studies have demonstrated that circulating miRNAs are packed into particular carriers and, therefore, protected from the degrading activity of RNAse enzymes, highly abundant in body fluids (23). Exosomes, microvesicles and apoptotic bodies, as well as lipoprotein complex (high-density lipoprotein (HDL)), all have been identified as non-cellular miRNAs carriers. However, the majority of circulating miRNAs seems associated in a stable complex with Argonaute-2 proteins (23). Despite the initial belief that non-cellular miRNAs were products of cell degradation with no specific functions, it has been suggested that these non-cellular miRNAs may represent signaling molecules with a definite role in cell-cell communication (24). Likely to cellular miRNAs, studies suggested that changes in the profile of circulating miRNAs are correlated with a pathophysiological condition of human cancer. In line with this concept, data achieved from our studies indicated that blood levels of miR-22, miR-24 and miR-34a are correlated with advanced stages of non-small cell lung cancer (NSCLC) (25). Also, several other cell-free miRNAs (e.g. miR-429, miR-205, miR-200b, miR-203, miR-125b and miR-34b) have been validated as diagnostic tools in NSCLC (26), as well as gastric cancer (27). Furthermore, studies demonstrated that high plasma levels of miR-19a are a favorable prognostic factor in patients with metastatic HER2+ inflammatory breast cancer (28).

At present, several clinical trials are investigating circulating miRNAs as biomarkers. For example, in patients with glioma associated with neurofibromatosis type 1 (NF-1) (ClinicalTrials.gov Identifier: NCT01595139), the microRNAs blood profile is being evaluated to identify circulating microRNAs that would be suitable as predictive/diagnostic markers for glioma associated with NF-1. Also, many clinical studies are focusing on detecting circulating miRNAs biomarkers in breast cancer (ClinicalTrials.gov, NCT02065908 and NCT0172285), hepatocellular carcinoma (ClinicalTrials.gov, NCT02448056), as well as pediatric cancer (ClinicalTrials.gov, NCT01541800). 


\section{Challenges of Circulating miRNAs in Cancer Diagnosis}

The discovery of circulating miRNAs has suggested the use of these microRNA molecules as biomarkers. In fact, noncellular miRNAs characteristics, namely their extraordinary resistance to degrading processes, and miRNAs presence in body fluids, which makes them detectable with non-invasive techniques, together with their correlation with pathological conditions, have made these cell-free molecules suitable candidates as predictive factors, as well as diagnostic markers.

However, studies in both cancer and non-neoplastic field, devoted in placing circulating miRNAs among biological markers, remain still much elusive. The effort in finding specific miRNAs for each disease has failed (29). In fact, several miRNAs has been found associated with a broad range of conditions. For example, the non-cellular miR-141 has been reported in the blood of pregnant women (30), as well as in patients with prostate and several other cancers (31). That has raised an important question: What does a change in the circulating miRNA profile mean? Is it a biomarker of a particular condition or a simple sign of a general state of the disease? (29). As suggested by Witwer the answer to this question depends on what we contemplate as cell-free miRNAs (29). We can assume that the pool of circulating miRNAs contains two types of miRNAs: miRNAs complexed with the Argonaute-2 proteins and vesicle-packed miRNAs (23). Currently, the common idea is that microRNAs encapsulated in the exosomes participate in intracellular signaling. Conversely, miRNAs-Argonaute-2 proteins complexes represent only cell by-products that accumulate in the extracellular fluids (23). This suggests that one way to identify miRNAs suitable as biomarkers should be in focalizing the attention on vesicular miRNAs, instead of continuing the study of the entire circulating pool of molecules (29).

\section{MicroRNA as Therapeutic Target}

MicroRNAs have been demonstrated to regulate fundamental cellular processes and, thus, their alteration has been correlated with a variety of human cancers. Due to their central role in human biology, a great enthusiasm has been posed in the use of miRNAs as a target in cancer therapy. Currently, several technologies are available to manipulate specific miRNAs, resulting in either their activation or inhibition $(32,33)$. The most common approaches used to abolish the miRNAs functionality consists of synthetic antisense oligonucleotides (ASOs) $(34,35)$. Despite the poor stability of these molecules, ASOs can be chemically manipulated to enhance their pharmacokinetics (33). Regardless the chemical modification, ASOs are commonly referred as anti-miRs (33). However, cholesterol-conjugated ASOs are termed antagomirs $(34,35)$. Anti-miRs bind native miRNAs, through base pair matching, and prevent miRNAmRNA interaction (33). The same concept of antisense complementarity has been used to realize miRNA sponges. A miRNA sponge consists of multiple miRNAs antisense molecules linked together to form a unique structure that can sequester and knockdown the activity of an entire pool of sequence-correlated miRNAs (36). The miRNA inhibition transcript can also be carried out by using specific drugs that alter the biogenesis of the mature miRNA transcript $(37,38)$.

The last decade has witnessed a considerable increase in cancer researchers devoted to exploring the therapeutic capability of miRNAs (39). The manipulation of miRNAs has been showed to undermine cancer progression. The reactivation of tumor suppressor miRNAs, such as miR-29b or miRNA-30-5p, in myeloma cells, has therapeutic effects $(40,41)$. On the other hand, miR-21 has been demonstrated to have an oncogenic feature (42). We proved that inhibition of the miR-21 halts the progression of multiple myeloma (MM) (43). In addition to blood cancer, the therapeutic potential of miRNAs has been addressed in different types of cancer including, but not limited to, glioblastoma (44), retinoblastoma (45) and leukemia (46).

\section{Challenges of miRNA-based Therapies}

MiRNA-based therapies pose challenges correlated to miRNA tissue-specific delivery and toxicity. The poor relative stability in the biological fluid, as well as the negative charge of mRNA molecules, make difficult the cellular uptake of miRNAs and their specific distribution into tissue $(47,48)$. To overcome these obstacles many strategies, including viral vector transportation, nanoparticle and cationic lipids inclusion, as well as chemical modification, have been investigated (49-53). However, approaches, such as anti-miRs and cationic lipids-linked miRNAs delivery, have elicited toxicity in vivo (39). Given miRNA-based therapies, an additional aspect to consider is that miRNAs regulate several diverse genes. Therefore, manipulation of these molecules could create side-effects and increase the risk of toxic phenotypes $(47,49)$.

\section{Conclusion}

As miRNAs are still an evolving research field, our awareness of miRNA biogenesis function is still at its infancy stage. Overall, miRNAs have demonstrated to be potentially valuable tools both in cancer diagnostic and therapy. However, a greater effort should be made to improve our approach, both technically and rationally, toward miRNAs biology, to overcame current challenges linked to the use of miRNAs. The consideration of Witwer 
about microRNAs in cancer diagnostics is remarkable (29). The author suggested placing our attention on investigating only the fraction of vesicular miRNAs, as this is the unique pool of circulating miRNAs that likely retain a biological function. In our point of view, an advanced understanding of the mechanism governing the biology of these molecules represents the only valid approach to design a useful diagnostic miRNA-based tool.

Nevertheless, from the therapeutic standpoint, Garzon et al. consider critical to establish new methods that enable the efficient delivery of specific miRNAs in cancer tissue (39). In agreement with these authors, we believe that this approach would help find a suitable therapeutic solution against the progression and recurrence of cancer, as well as to minimize the risk of toxic effects elicited by the administration of miRNA-based drug.

\section{Acknowledgements}

This work was supported by the Pennsylvania Department of Health for Sbarro Health Research Organization (SHRO) and the Italian Association for Cancer Research (Associazione Italiana per la Ricerca sul Cancro, AIRC).

\section{References}

1 Palazzo AF and Lee ES: Non-coding RNA: What is functional and what is junk? Front Genet 26;6: 2, 2015. doi: 10.3389/fgene.2015.00002.

2 Ghildiyal $M$ and Zamore PD: Small silencing RNAs: an expanding universe. Nat Rev Genet 10: 94-108, 2009.

3 Garofalo M, Condorelli GL, Croce CM and Condorelli G: MicroRNAs as regulators of death receptors signaling. Cell Death Differ 17: 200-208, 2010.

4 Sacco J and Adeli K: MicroRNAs: emerging roles in lipid and lipoprotein metabolism. Curr Opin Lipidol 23: 220-225, 2012.

5 Ivey $\mathrm{KN}$ and Srivastava D: MicroRNAs as regulators of differentiation and cell fate decisions. Cell Stem Cell 7: 36-41, 2010.

6 Gangaraju VK and Lin H: MicroRNAs: key regulators of stem cells. Nat Rev Mol Cell Biol 10: 116-25, 2009.

7 Hussain MU: Micro-RNAs (miRNAs): Genomic organisation, biogenesis and mode of action. Cell Tissue Res 349: 405-413, 2012.

8 Maqbool R and Hussain MU: MicroRNAs and human diseases: diagnostic and therapeutic potential. Cell Tissue Res 358: 1-15, 2014.

9 Ruby JG, Jan CH and Bartel DP: Intronic microRNA precursors that bypass Drosha processing. Nature 448: 83-86, 2007.

10 Wen J, Ladewig E, Shenker S, Mohammed J and Lai EC: Analysis of Nearly One Thousand Mammalian Mirtrons Reveals Novel Features of Dicer Substrates. PLoS Comput Biol 1;11(9): e1004441, 2015 doi: 10.1371/journal.pcbi.1004441.

11 Benoit MPMH, Imbert L, Palencia A, Pérard J, Ebel C, Boisbouvier $\mathrm{J}$ and Plevin MJ: The RNA-binding region of human TRBP interacts with microRNA precursors through two independent domains. Nucleic Acids Res 41: 4241-4252, 2013.
$12 \mathrm{He}$ L and Hannon GJ: MicroRNAs: small RNAs with a big role in gene regulation. Nat Rev Genet 5: 522-531, 2004.

13 Xi JJ: MicroRNAs in cancer. Cancer Treat Res 158: 119-137, 2013.

14 Cattaneo M, Pelosi E, Castelli G, Cerio AM, D'Angiò A, Porretti L, Rebulla P, Pavesi L, Russo G, Giordano A, Turri J, Cicconi L, Lo-Coco F, Testa U and Biunno I: A miRNA signature in human cord blood stem and progenitor cells as potential biomarker of specific acute myeloid leukemia subtypes. J Cell Physiol 230(8): 1770-1780, 2014.

15 Reddy KB: MicroRNA (miRNA) in cancer. Cancer Cell Int 15: $38,2015$.

16 Amodio N, Bellizzi D, Leotta M, Raimondi L, Biamonte L, D'Aquila P, Di Martino MT, Calimeri T, Rossi M, Lionetti M, Leone E, Passarino G, Neri A, Giordano A, Tagliaferri P and Tassone P: miR-29b induces SOCS-1 expression by promoter demethylation and negatively regulates migration of multiple myeloma and endothelial cells. Cell Cycle 12: 3650-3662, 2013.

17 Rossi M, Pitari MR, Amodio N, Di Martino MT, Conforti F, Leone E, Botta C, Paolino FM, Del Giudice T, Iuliano E, Caraglia M, Ferrarini M, Giordano A, Tagliaferri P and Tassone P: miR-29b negatively regulates human osteoclastic cell differentiation and function: Implications for the treatment of multiple myeloma-related bone disease. J Cell Physiol 228(7): 1506-1515, 2012.

18 Olive V, Li Q and He L: mir-17-92: A polycistronic oncomir with pleiotropic functions. Immunol Rev 253: 158-166, 2013.

19 Esquela-Kerscher A and Slack FJ: Oncomirs - microRNAs with a role in cancer. Nat Rev Cancer 6: 259-269, 2006.

20 Calin GA, Dumitru CD, Shimizu M, Bichi R, Zupo S, Noch E, Aldler H, Rattan S, Keating M, Rai K, Rassenti L, Kipps T, Negrini M, Bullrich F and Croce CM: Frequent deletions and down-regulation of micro- RNA genes miR15 and miR16 at 13 q14 in chronic lymphocytic leukemia. Proc Natl Acad Sci USA 99: 15524-15529, 2002.

21 Toyota M, Suzuki H, Sasaki Y, Maruyama R, Imai K, Shinomura $\mathrm{Y}$ and Tokino T: Epigenetic silencing of microRNA-34b/c and Bcell translocation gene 4 is associated with $\mathrm{CpG}$ island methylation in colorectal cancer. Cancer Res 68: 4123-4132, 2008.

22 Kumar MS, Lu J, Mercer KL, Golub TR and Jacks T: Impaired microRNA processing enhances cellular transformation and tumorigenesis. Nat Genet 39: 673-677, 2007.

23 Turchinovich A, Weiz L, Langheinz A and Burwinkel B: Characterization of extracellular circulating microRNA. Nucleic Acids Res 39: 7223-7233, 2011.

24 Hruštincová, Votavová and Dostálová Merkerová: Circulating MicroRNAs: Methodological Aspects in Detection of These Biomarkers. Folia Biol (Praha) 61: 203-218, 2015.

25 Franchina T, Amodeo V, Bronte G, Savio G, Ricciardi GRR, Picciotto M, Russo A, Giordano A and Adamo V: Circulating miR-22, miR-24 and miR-34a as Novel Predictive Biomarkers to Pemetrexed-Based Chemotherapy in Advanced Non-Small Cell Lung Cancer. J Cell Physiol 229: 97-99, 2014.

26 Halvorsen, AR, Bjaanæs, M, LeBlanc,M, Holm, AM, Bolstad, N, Rubio, L, Peñalver, JC, Cervera, J, Mojarrieta, JC, LópezGuerrero, JA, Brustugun, OT, Helland A: A unique set of 6 circulating microRNAs for early detection of non-small cell lung cancer. Oncotarget 2016. doi: 10.18632/oncotarget.9363.

27 Qiu X, Zhang J, Shi W, Liu S, Kang M, Chu H, Wu D, Tong N, Gong W, Tao G, Zhao Q, Qiang F, Zhu H, Wu Q, Wang M and 
Zhang Z: Circulating microRNA-26a in plasma and its potential diagnostic value in gastric cancer. PLoS One 11: e0151345, 2016.

28 Anfossi S, Giordano A, Gao H, Cohen EN, Tin S, Wu Q, Garza RJ, Debeb BG, Alvarez RH, Valero V, Hortobagyi GN, Calin GA, Ueno NT, Woodward WA and Reuben JM: High serum miR-19a levels are associated with inflammatory breast cancer and are predictive of favorable clinical outcome in patients with metastatic HER2+ inflammatory breast cancer. PLoS One 9: e83113, 2014

29 Witwer KW: Circulating MicroRNA biomarker studies: Pitfalls and potential solutions. Clin Chem 61: 56-63, 2015.

30 Chim SSC, Shing TKF, Hung ECW, Leung TY, Lau TK, Chiu RWK and Lo YMD: Detection and characterization of placental microRNAs in maternal plasma. Clin Chem 54: 482-490, 2008.

31 Mitchell PS, Parkin RK, Kroh EM, Fritz BR, Wyman SK, Pogosova-Agadjanyan EL, Peterson A, Noteboom J, O'Briant KC, Allen A, Lin DW, Urban N, Drescher CW, Knudsen BS, Stirewalt DL, Gentleman R, Vessella RL, Nelson PS, Martin DB and Tewari M: Circulating microRNAs as stable blood-based markers for cancer detection. Proc Natl Acad Sci USA 105: 10513-10518, 2008.

32 Van Rooij E, Purcell AL and Levin AA: Developing MicroRNA therapeutics. Circ Res 110: 496-507, 2012.

33 Abba ML, Patil N, Leupold JH, Moniuszko M, Utikal J, Niklinski $\mathrm{J}$ and Allgayer H: MicroRNAs as novel targets and tools in cancer therapy. Cancer Lett 2016. doi: 10.1016/j.canlet.2016.03.043

34 Krützfeldt J, Rajewsky N, Braich R, Rajeev KG, Tuschl T, Manoharan $\mathrm{M}$ and Stoffel $\mathrm{M}$ : Silencing of microRNAs in vivo with "antagomirs". Nature 438: 685-689, 2005.

35 Krützfeldt J, Kuwajima S, Braich R, Rajeev KG, Pena J, Tuschl T, Manoharan M and Stoffel M: Specificity, duplex degradation and subcellular localization of antagomirs. Nucleic Acids Res 35: 2885-2892, 2007.

36 Ebert MS, Neilson JR and Sharp P a: MicroRNA sponges: competitive inhibitors of small RNAs in mammalian cells. Nat Methods 4: 721-726, 2007.

37 Velagapudi SP, Gallo SM and Disney MD: Sequence-based design of bioactive small molecules that target precursor microRNAs. Nat Chem Biol 10: 291-297, 2014.

38 Tor Y: Targeting RNA with small molecules. ChemBioChem 4: 998-1007, 2003.

39 Garzon R, Marcucci G and Croce CM: Targeting microRNAs in cancer: rationale, strategies and challenges. Nat Rev Drug Discov 9: 775-789, 2010.

40 Amodio N, Di Martino MT, Foresta U, Leone E, Lionetti M, Leotta M, Gullà AM, Pitari MR, Conforti F, Rossi M, Agosti V, Fulciniti M, Misso G, Morabito F, Ferrarini M, Neri A, Caraglia M, Munshi NC, Anderson KC, Tagliaferri P and Tassone P: miR$29 \mathrm{~b}$ sensitizes multiple myeloma cells to bortezomib-induced apoptosis through the activation of a feedback loop with the transcription factor Sp1. Cell Death Dis 3: e436, 2012.

41 Zhao JJ, Lin J, Zhu D, Wang X, Brooks D, Chen M, Chu ZB, Takada K, Ciccarelli B, Admin S, Tao J, Tai YT, Treon S, Pinkus G, Kuo WP, Hideshima T, Bouxsein M, Munshi N, Anderson K and Carrasco RD: MiR-30-5p functions as a tumor suppressor and novel therapeutic tool by targeting the oncogenic Wnt/ bCatenin/BCL9 pathway. Cancer Res 74: 1801-1813, 2014.
42 Wang X, Li C, Ju S, Wang Y, Wang H and Zhong R: Myeloma cell adhesion to bone marrow stromal cells confers drug resistance by microRNA-21 up-regulation. Leuk Lymphoma 52: 1991-1998, 2011.

43 Leone E, Morelli E, Di Martino MT, Amodio N, Foresta U, Gullà A, Rossi M, Neri A, Giordano A, Munshi NC, Anderson $\mathrm{KC}$, Tagliaferri $\mathrm{P}$ and Tassone $\mathrm{P}$ : Targeting miR-21 inhibits in vitro and in vivo multiple myeloma cell growth. Clin Cancer Res 19: 2096-2106, 2013.

44 Silber J, Lim D a, Petritsch C, Persson AI, Maunakea AK, Yu M, Vandenberg SR, Ginzinger DG, James CD, Costello JF, Bergers G, Weiss W a, Alvarez-Buylla A and Hodgson JG: miR124 and miR-137 inhibit proliferation of glioblastoma multiforme cells and induce differentiation of brain tumor stem cells. BMC Med 6: 1741-7015, 2008.

45 Subramanian N, Kanwar JR, Kanwar RK and Krishnakumar S: Blocking the Maturation of OncomiRNAs Using pri-miRNA-17 similar to 92 Aptamer in Retinoblastoma. Nucleic Acid Ther 25: 47-52, 2015.

46 Volinia S, Galasso M, Costinean S, Tagliavini L, Gamberoni G, Drusco A, Marchesini J, Mascellani N, Sana ME, Jarour RA, Desponts C, Teitell M, Baffa R, Aqeilan R, Iorio M V., Taccioli C, Garzon R, Di Leva G, Fabbri M, Catozzi M, Previati M, Ambs S, Palumbo T, Garofalo M, Veronese A, Bottoni A, Gasparini P, Harris CC, Visone R, Pekarsky Y, De La Chapelle A, Bloomston M, Dillhoff M, Rassenti LZ, Kipps TJ, Huebner K, Pichiorri F, Lenze D, Cairo S, Buendia MA, Pineau P, Dejean A, Zanesi N, Rossi S, Calin GA, Liu CG, Palatini J, Negrini M, Vecchione A, Rosenberg A and Croce CM: Reprogramming of miRNA networks in cancer and leukemia. Genome Res 20: 589$599,2010$.

47 Aagaard L and Rossi JJ: RNAi therapeutics: Principles, prospects and challenges. Adv Drug Deliv Rev 59: 75-86, 2007.

48 Zhao X, Pan F, Holt CM, Lewis AL and Lu JR: Controlled delivery of antisense oligonucleotides: a brief review of current strategies. Expert Opin Drug Deliv 6: 673-686, 2009.

49 Dias N and Stein CA: Antisense Oligonucleotides: Basic Concepts and Mechanisms. Mol Cancer Ther 1: 347-355, 2002.

50 Malik R and Roy I: Design and development of antisense drugs. Expert Opin Drug Discov 3: 1189-1207, 2008.

51 Chiarantini L, Cerasi A, Fraternale A, Millo E, Benatti U, Sparnacci K, Laus M, Ballestri M and Tondelli L: Comparison of novel delivery systems for antisense peptide nucleic acids. J Control Release 109: 24-36, 2005.

52 Zuhorn IS, Engberts JBFN and Hoekstra D: Gene delivery by cationic lipid vectors: Overcoming cellular barriers. Eur Biophys J 36: 349-362, 2007.

53 Chirila TV, Rakoczy PE, Garrett KL, Lou X and Constable IJ: The use of synthetic polymers for delivery of therapeutic antisense oligodeoxynucleotides. Biomaterials 23: 321-342, 2002.
Received August 9, 2016

Revised August 23, 2016

Accepted August 26, 2016 